\title{
Artificial Neural Network Based Model Predictive Control Vis-à-vis Simple On-Off Control of Windows Opening Position for Mixed-Mode-Operated Building
}

\author{
Brijesh Pandey $^{1}$, Rajat Pungaliya ${ }^{2}$, Rangan Banerjee ${ }^{1}$ \\ ${ }^{1}$ Department of Energy Science and Engineering, IIT Bombay, Mumbai, India \\ ${ }^{2}$ School of Mechanical Engineering, VIT University, Vellore, India
}

\begin{abstract}
This paper presents an artificial neural network (ANN) based model predictive control to implement the mixedmode strategy in buildings. Simple heuristics are unable to incorporate the occupant interaction with the built environment whereas; significant efforts are required to configure and calibrate the model used in the model predictive controller. To address the above issues an ANN-based predictive controller is developed, and used within EnergyPlus-Matlab co-simulation framework with particle swarm optimization (PSO) as an optimizer. Simulations are performed for the five consecutive days for January with mixed-mode control strategy. The results show significant cooling energy savings compared to the rule-based heuristic.
\end{abstract}

\section{Introduction}

Commercial buildings in India represent a significant and growing contribution (annual growth rate of stock 5.4\%) to electricity demand in India. Air conditioning accounts for $31 \%$ of the total electricity use in commercial buildings. At present, a large portion of the building stock is cooled with natural ventilation and ceiling fans. As the economy develops most of the new commercial buildings are likely to be air-conditioned, and the share of air conditioning in the total electricity use is expected to increase.

A mixed-mode building provides the flexibility of using naturally ventilated techniques and air-conditioning based on the requirement. A mixed-mode strategy has the potential of reducing electricity consumption as compared to HVAC (Heating Ventilation and Air Conditioning) alone strategies while providing the same level of thermal comfort. Mixed-mode building operation is generally categorized into the following three modes:

1. Underzoned: natural and mechanical ventilation is allowed to happen simultaneously at the same time but in different zones.

2. Concurrent: natural and mechanical ventilation may happen at the same time and space.

3. Changeover: natural and mechanical ventilation is allowed to happen at the same space but not at the same time.

Mixed-mode strategy in the built environment can be implemented effectively using controllers which respond to disturbance variables (such as human interaction with buildings and weather parameter) and control the building
HVAC system and window openings appropriately. Generally, two approaches such as; simple rule based on/off control and model-based predictive control is reported in the literature to implement the mixed-mode strategy in the built environment

Simple rule-based controllers depend on the simple heuristics (if-then) and provide control to the windows and HVAC systems according to specified rules. For example, if the outdoor environmental parameters such as outdoor temperature and wind speed lie within a specific range open windows and shut down the HVAC system otherwise close window and start the HVAC system. The rule-based heuristic decides the control action based on the current state of the system.

A model predictive controller is a controller that provides an optimal control sequence to the system by optimizing the operating cost and occupant thermal comfort based on the local weather forecast and cooling load anticipation. A model-based predictive controller requires a simplified model which can correlate between input and output variables. For mixed-mode operated buildings formulating the simplified model and training that model is complicated because of the coupled interaction between thermal, airflow dynamics and HVAC systems. Extensive experimental data is needed to train the model which limits the practical applicability of the model-based predictive controller.

Generally, mixed-mode buildings are not equipped with building automation systems. Heuristics developed by HVAC engineers are sent to the occupants as a notification in the form of light signals, and occupants have to actuate the windows accordingly (McConahey, 2008). However, involving the occupants in the control process undermine the energy savings, since people cannot be expected to operate their windows in an energy efficient manner all the time. An autonomous system is required which can actuate the windows and HVAC system simultaneously in the built environment by taking environmental disturbances into account and learning the pattern of occupants' interaction with buildings.

Braun (1990) developed a model in the form of a transfer function using the simplified building and cooling system models which were used to identify the optimal trajectories for zone and HVAC set-points over 24-hour prediction horizon period. The coefficient of the transfer function was estimated by applying nonlinear regression to the results of the detailed model. However, as today's 
buildings are operated with multiple modes (such as naturally ventilated mode, mixed-mode (change over, concurrent and underzoned) and air-conditioned mode) and multilayer coordination between different systems simple model no longer would be an appropriate method for the efficient building control

Spindler and Norford (2008) used an extensive set of experimental data to train the inverse model for finding the optimal cooling mode for a multi-zone mixed-mode building. The inverse model is a promising approach to control the windows opening, but its performance is dependent on experimental data. Quality and accessibility of data to develop the inverse model depend on the accuracy of data collection. Sometimes data may corrupt due to failure in the transmission line and improper positioning of sensors.

May-Ostendrop (2011) used EnergyPlus to simulate a small DOE office building operated in a mixed-mode manner. They used the PSO (Particle Swarm Optimization) algorithm to generate optimal window opening schedules. They further used the simulated results to extract near optimal heuristics using statistical technique and supervisory building control rules.

Jianjun (2014) developed a forward LTV-SS (Linear Time-Varying State Space) model using a physics-based approach to represent the mixed-mode operation of a building. Further, they used progressive refinement optimization technique following the multi-level optimization topology branch and bound method to find the sequence of binary (open/close) decision for the motorized windows. The challenges associated with the model discussed by the author are the complexities of the model such as; the number of order, states and lumping. The model order should be such that it should sufficiently capture the building performance. Furthermore, calibrating the model with real building performance is challenging. Keeping the challenges mentioned above in view developing a white box model may be difficult and costly.

Zhao (2015) used EnergyPlus and Matlab/Simulink cosimulation environment for the occupant oriented mixedmode EnergyPlus predictive control. However, the author has not mentioned about the method of data generation to make a model for predictive control. Neither about the selection of system identification technique nor about the number of states has been mentioned.

Table 1 summarized the above-discussed literature review which provides brief insights of the methodologies reported in the literature and their limitations.

Analysing the literature in the context of mixed-mode the gaps in the literature can be categorized into the following broad categories

1. The simple rule-based controllers are ineffective for the current requirement of advance control of HVAC systems and windows opening.

2. Formulation of the model for model predictive control which can be further categorized into the following sub-categories:
- Complexities in choosing the correct model such as; physics-based (white box) model, grey box model, and black box model

- Data acquisition technique for the estimation of model

- Calibration of the model with the real building performance

- Choice and implementation of the system identification method

Table 1: Models for mixed-mode implementation in buildings

\begin{tabular}{|c|c|c|}
\hline Author & $\begin{array}{c}\text { Control } \\
\text { Techniques }\end{array}$ & $\begin{array}{c}\text { Deficiency of } \\
\text { the model }\end{array}$ \\
\hline $\begin{array}{l}\text { McConahey } \\
\text { (2008) }\end{array}$ & $\begin{array}{c}\text { Simple } \\
\text { Heuristics }\end{array}$ & $\begin{array}{l}\text { Does not } \\
\text { incorporate the } \\
\text { disturbances } \\
\text { (such as } \\
\text { occupants } \\
\text { interaction with } \\
\text { the built } \\
\text { environment } \\
\text { and future } \\
\text { environmental } \\
\text { variables) }\end{array}$ \\
\hline Braun (1990) & $\begin{array}{c}\text { Simplified } \\
\text { building and } \\
\text { cooling system } \\
\text { models }\end{array}$ & $\begin{array}{l}\text { Not applicable } \\
\text { for the current } \\
\text { complex } \\
\text { building } \\
\text { operation }\end{array}$ \\
\hline $\begin{array}{l}\text { Spindler and } \\
\text { Norford (2008) }\end{array}$ & $\begin{array}{l}\text { Inverse model } \\
\text { approach }\end{array}$ & $\begin{array}{c}\text { Dependent on } \\
\text { experimental } \\
\text { data. } \\
\text { Quality, } \\
\text { accessibility, } \\
\text { and accuracy of } \\
\text { data }\end{array}$ \\
\hline $\begin{array}{l}\text { May-Ostendrop } \\
\text { (2011) }\end{array}$ & $\begin{array}{l}\text { Model-based } \\
\text { predictive } \\
\text { controller }\end{array}$ & $\begin{array}{l}\text { The complexity } \\
\text { of the model } \\
\text { such as; the } \\
\text { number of } \\
\text { order, states and } \\
\text { lumping. } \\
\text { Calibration of } \\
\text { the model with } \\
\text { real building } \\
\text { performance }\end{array}$ \\
\hline
\end{tabular}

The study presented in this paper aims to develop a control oriented modeling approach along with an efficient solution for the optimal control problem to facilitate the implementation of ANN (Artificial Neural Network) based model predictive control algorithms with PSO (Particle Swarm Optimization) technique in a prototype (eight-storeyed with floor area $12875 \mathrm{~m}^{2}$ ) multi-zone building with mixed-mode cooling. An ANN model is created by performing the whole building simulation of the prototype building using EnergyPlus weather data (epw format) for Mumbai, India. PSO (Particle Swarm Optimization) framework is used using the ANN model as an objective function to minimize the energy. Zone set-point and windows opening position are used as search space. 


\section{Building description}

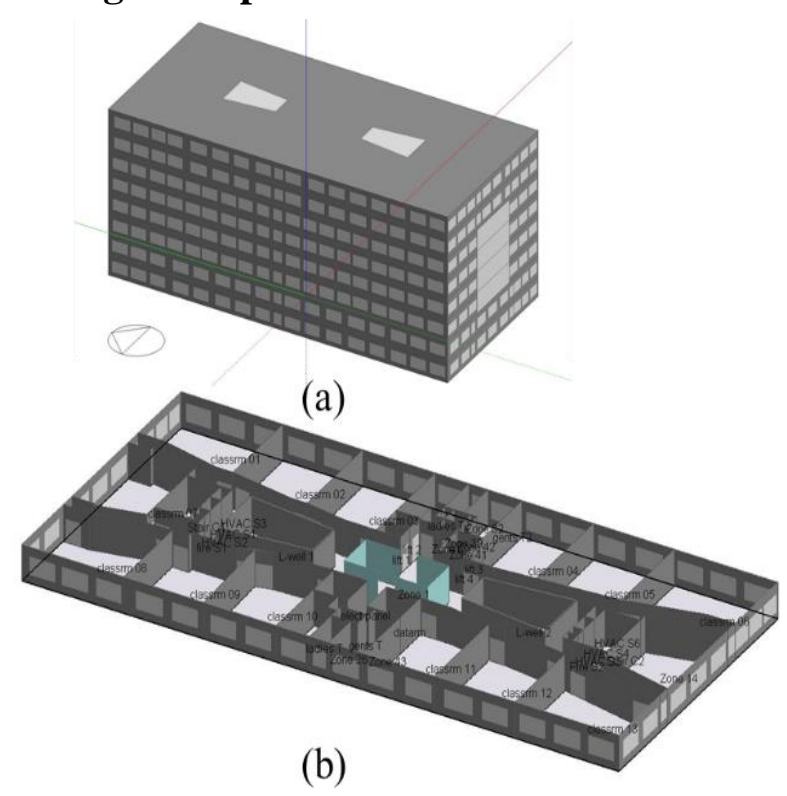

Figure 1: Model view in design builder. (a) whole building model and (b) first floor zoning

The building mentioned in the previous section is equipped with VAV (Variable Air Volume) reheat water cooled chiller with full humidity control. Service spaces such as restrooms, mechanical rooms, and storage rooms are not considered in the conditioned area. The building is oriented towards north-south. There are 13 occupied zones on each floor of the building. All the occupied zones are along the perimeter of the building, and the central part of the building is used as a light well. All the occupied zones are equipped with operable windows of dimension $2.5 \mathrm{~m} \times 1.7 \mathrm{~m}$. The EnergyPlus model is created using Design Builder (version 4.5.0.148). Figure 1(a) shows the EnergyPlus building model and Figure 1(b) shows the zoning of the first floor. Thermostat set-point of each zone is kept between $24-26^{\circ} \mathrm{C}$ with relative humidity between $55-60 \%$. Building materials' property, internal load, and occupied zone's area and volume are shown in Table 2, 3, and 4 respectively.

\section{Table 2: Building materials' property}

\begin{tabular}{|c|c|c|}
\hline $\begin{array}{c}\text { Building } \\
\text { Component }\end{array}$ & Thickness (m) & $\begin{array}{c}\text { U-Value }(\boldsymbol{W} / \\
\left.\boldsymbol{m}^{\mathbf{2}} \boldsymbol{K}\right)\end{array}$ \\
\hline Wall & 0.1 & 2.22 \\
\hline Window & 0.019 & 2.08 \\
\hline $\begin{array}{c}\text { Internal wall } \\
\text { Partition }\end{array}$ & 0.15 & 1.85 \\
\hline Floor & 0.33 & 1.11 \\
\hline Roof & 0.37 & 1.08 \\
\hline
\end{tabular}

Table 3: Internal load of the occupied zone

\begin{tabular}{|c|c|}
\hline $\begin{array}{c}\text { Internal Load } \\
\text { (Per zone) }\end{array}$ & Value $\left(\boldsymbol{W} / \mathbf{m}^{\mathbf{2}}\right)$ \\
\hline Lighting & 5 \\
\hline Electrical & 11.8 \\
\hline
\end{tabular}

Table 4: Area and volume of the occupied zones of first floor

\begin{tabular}{|c|c|c|}
\hline $\begin{array}{c}\text { Occupied } \\
\text { Zones }\end{array}$ & Area $\left(\boldsymbol{m}^{\mathbf{2}}\right)$ & Volume $\left(\boldsymbol{m}^{\mathbf{3}}\right)$ \\
\hline Classroom 1 & 87.3 & 305.6 \\
\hline Classroom 2 & 79.2 & 277 \\
\hline Classroom 3 & 78.4 & 274.5 \\
\hline Classroom 4 & 77.9 & 272.7 \\
\hline Classroom 5 & 82.5 & 288.7 \\
\hline Classroom 6 & 89.6 & 313.8 \\
\hline Classroom 7 & 71.7 & 250.8 \\
\hline Classroom 8 & 84.1 & 294.3 \\
\hline Classroom 9 & 74.2 & 259.7 \\
\hline Classroom 10 & 77.4 & 271 \\
\hline Classroom 11 & 74.9 & 262.3 \\
\hline Classroom 12 & 78.9 & 275.9 \\
\hline Classroom 13 & 85.4 & 299 \\
\hline
\end{tabular}

Figure 2 shows the occupancy and equipment schedules of the thermally occupied zone.

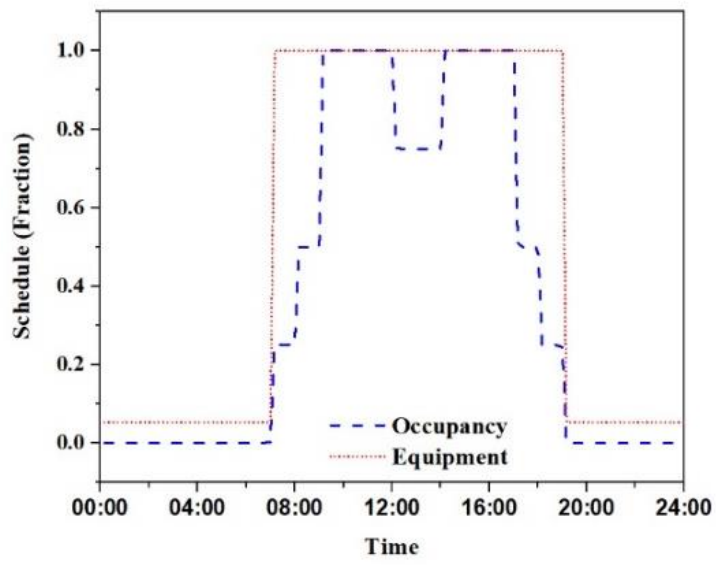

Figure 2: Occupancy and Equipment schedule

\section{Climate analysis for mixed-mode operation}

For the mixed-mode operation of the building, dry bulb temperature should be in the range between $15.5-27^{\circ} \mathrm{C}$, and upper and lower limits for the relative humidity and dew point temperature should be less than $70 \%$ and greater than $18^{\circ} \mathrm{C}$ respectively (Borgeson, 2011). To apply the mixed-mode strategy in this study the first week of January is considered. First of all, January is considered because of the high potential of deploying the natural ventilation strategy. Climate consultant analysis using ASHRAE standard 55 PMV-PPD model shows that for 316 out of 744 hours, natural ventilation is deployable which is highest compared to other months. Further analysis shows that the highest potential of deploying natural ventilation is in the first week of January. Figure 3 shows the comfortable hours using natural ventilation for four weeks of January. Figure 4 shows the dry bulb temperature, dew point temperature, and relative humidity for the first week of January. Out of the total 169 hours of the simulation period, 117 hours of the dry bulb temperature, 101 hours of relative humidity and 6 hours of dew point temperature satisfy the criteria mentioned above of mixed-mode operation of the building. 
Table 5: Rule constraints to actuate the windows

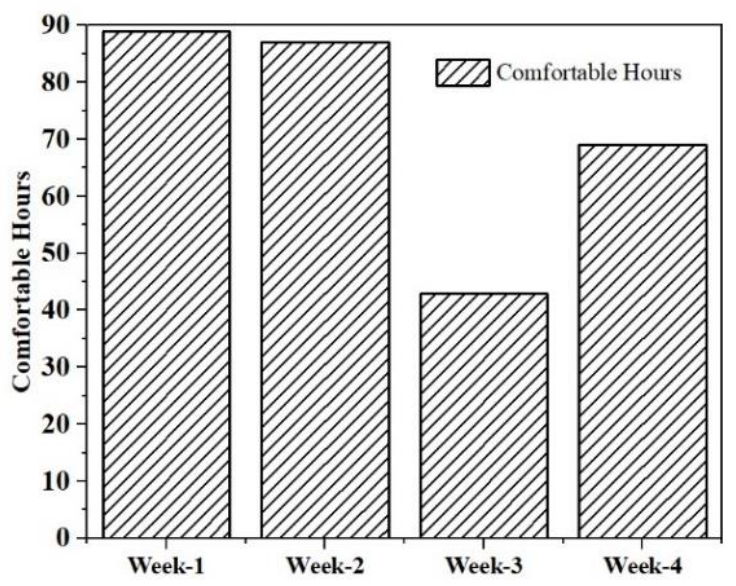

Figure 3: Weekly thermal comfort hours for January

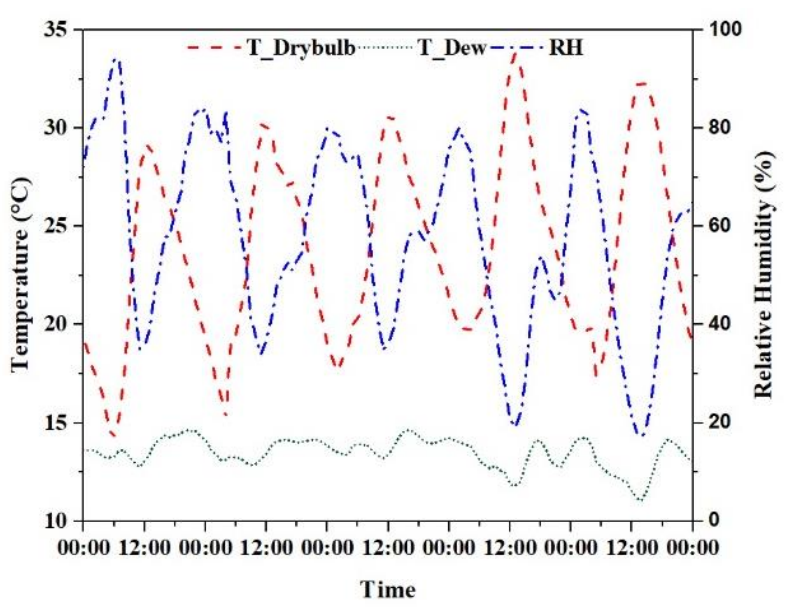

Figure 4: Weather condition used for simulation

\section{Mixed-mode cooling concept implementation and baseline control design}

To develop the baseline control design for mixed-mode operation of the building Energy Management System (EMS) object of EnergyPlus is used. Outdoor dry bulb temperature is used as a sensor to actuate the window opening position. Each window of the occupied zones is actuated based on outdoor dry bulb temperature using "Airflow Network Window Opening" actuator component type and "Venting Opening Factor" actuator control type. Based on the window opening position, setpoint of each occupied zone is actuated using "Schedule: Constant" as actuator component type and "Schedule value" as actuated component control type. Table 5 shows the control strategy applied as a baseline. Table 5 can be interpreted as if outdoor dry bulb temperature lies between $22-27^{\circ} \mathrm{C}$ and either dew point temperature is greater than $18^{\circ} \mathrm{C}$ or wind speed is less than $7.5 \mathrm{~m} / \mathrm{s}$ windows will be opened and zone cooling set-point will be raised to $26^{\circ} \mathrm{C}$ by above discussed EMS actuators for other conditions windows will be closed and zone setpoint temperature will be $24^{\circ} \mathrm{C}$.

\begin{tabular}{|c|c|c|c|}
\hline $\begin{array}{c}\text { Environmen } \\
\text { tal } \\
\text { Variable }\end{array}$ & Constraints & $\begin{array}{l}\text { Control } \\
\text { action } \\
\text { for } \\
\text { window }\end{array}$ & $\begin{array}{c}\text { Control } \\
\text { for zone } \\
\text { cooling } \\
\text { set-point }\end{array}$ \\
\hline $\begin{array}{l}\text { Outdoor dry } \\
\text { bulb } \\
\text { temperature }\end{array}$ & \multirow{4}{*}{$\begin{array}{r}22-27^{\circ} \mathrm{C} \\
>18^{\circ} \mathrm{C} \\
<7.5 \mathrm{~m} / \mathrm{s} \\
\end{array}$} & \multirow{3}{*}{1 (Open) } & \multirow{3}{*}{$26^{\circ} \mathrm{C}$} \\
\hline $\begin{array}{l}\text { Dew point } \\
\text { temperature }\end{array}$ & & & \\
\hline Wind speed & & & \\
\hline & & 0 (Close) & $24^{\circ} \mathrm{C}$ \\
\hline
\end{tabular}

\section{Artificial Neural Network (ANN) based control design}

ANN model-based predictive control design is implemented using EnergyPlus (version 8.5 Crawley, 2001) and Matlab R2014b co-simulation framework. MLE+ source code and BCVTB (Building Control Virtual Test Bed (Wetter, 2011)) are used to couple EnergyPlus and Matlab for co-simulation. ANN modelbased predictive controller is developed in Matlab and control action is provided for the occupied zone windows through "External Interface: Actuator" object of EnergyPlus. A two-layer feed-forward network with sigmoid hidden neurons and linear output neurons is used to create the ANN model. Outdoor dry bulb temperature, dew point temperature, thermal comfort variable (PMV (Predictive Mean Vote)), operative temperature, wind speed, and window opening schedule are used as input; cooling energy is used as target variable to train the ANN model. The Levenberg-Marquardt (Moré, 1978) backpropagation training algorithm is used to train the model. It is a network training function that updates weight and bias values.

For the ANN training, input and target data mentioned previously is generated using EnergyPlus "Availability manager: Hybrid Ventilation" technique which allows the natural ventilation to happen when the outdoor environmental parameters are in favorable condition. For the hybrid ventilation technique minimum and maximum outdoor dry bulb temperature was set as $22^{\circ} \mathrm{C}$ and $27^{\circ} \mathrm{C}$ respectively as in the rule-based controller.

Figure 5 shows the ANN architecture chosen to train the model. There are six input layers, one hidden layer containing ten neurons and one output layer. The number of neurons is selected considering the thumb rule that neurons in the hidden layer should be less than twice the number of input layers. Weights and biases are updated during the training process.

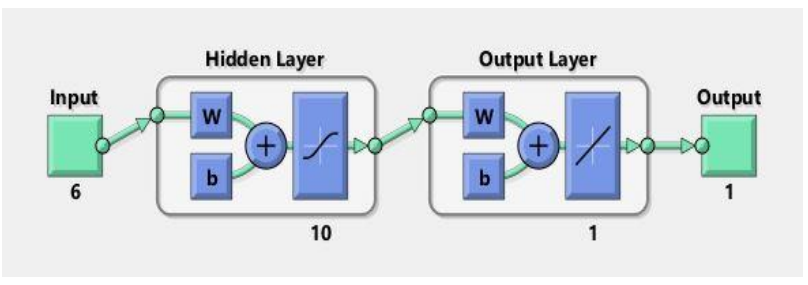

Figure 5: ANN architecture 


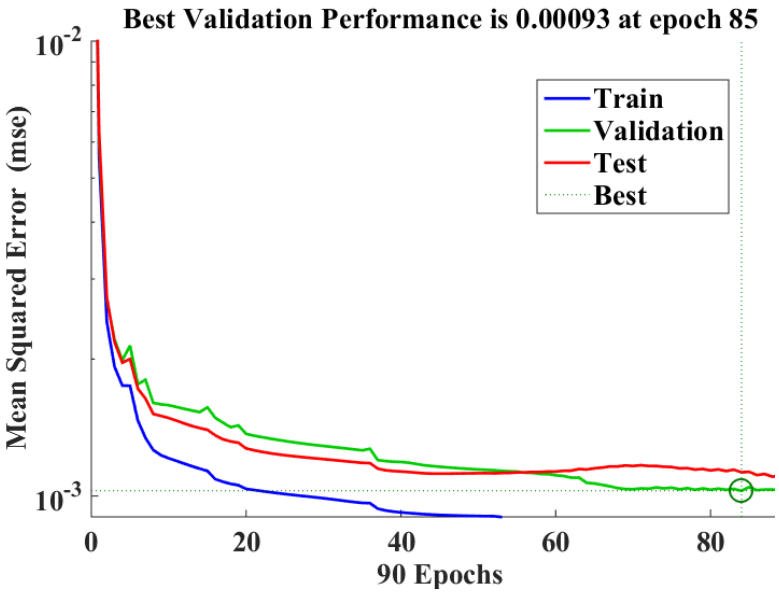

Figure 6: Performance analysis of ANN model

Figure 6 shows the performance analysis of the ANN model. The figure shows that the validation error first decreases to 3 epochs and after that error on the validation set begins rising to 20 epochs because network begins to overfit the data. After 20 epochs error on the validation set decreases gradually and approaches to a minimum at 85 epochs. Weights and biases are saved at a minimum of the validation set error which is used to test the model with testing data set.
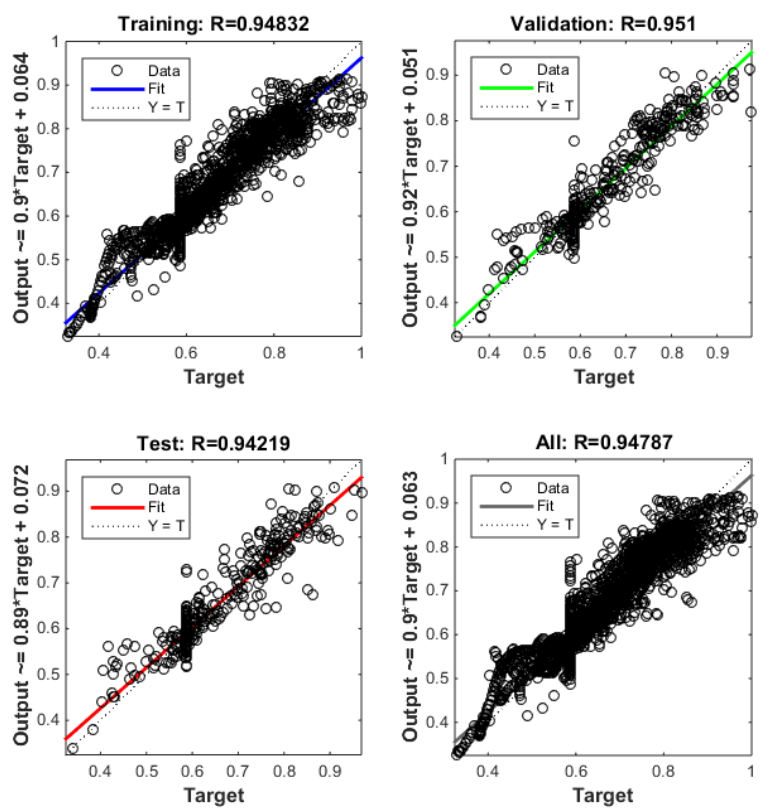

Figure 7: Testing and validation of the ANN network

Figure 7 shows the regression plot which presents the relationship between the outputs of the network and targets. $70 \%$ of the data is used as training data for computing the gradient and updating the network weights and biases. Remaining $30 \%$ of the data is used for validation $(15 \%)$ and testing $(15 \%)$. It can be observed that R-values for the validation and testing data are 0.95 and 0.94 respectively which show that the fitting model is in good agreement with the output data of the ANN model and target data.

Once the ANN network is formed it is used as an objective function for the minimization of cooling energy, and maximizing thermal comfort. Since there is no explicit form of the equation between the input and output variables, traditional gradient-based search technique cannot be applied to optimize the function. As a result, a meta-heuristic search technique, PSO is used for the quick and robust search of the decision space, and to find a nearoptimal solution. The mathematical formulation of the optimization framework can be given as:

Minimize: $Z=E$ (cooling energy)

subject to

Window opening: $I=\{0,1\}$

Wind speed $<7.5 \mathrm{~m} / \mathrm{s}$

Dew point temperature $\leq 13.5^{\circ} \mathrm{C}$

Operative temperature $\in\left[23^{\circ} \mathrm{C} 27^{\circ} \mathrm{C}\right]$

Thermal comfort $(P M V) \in[-0.5+0.5]$

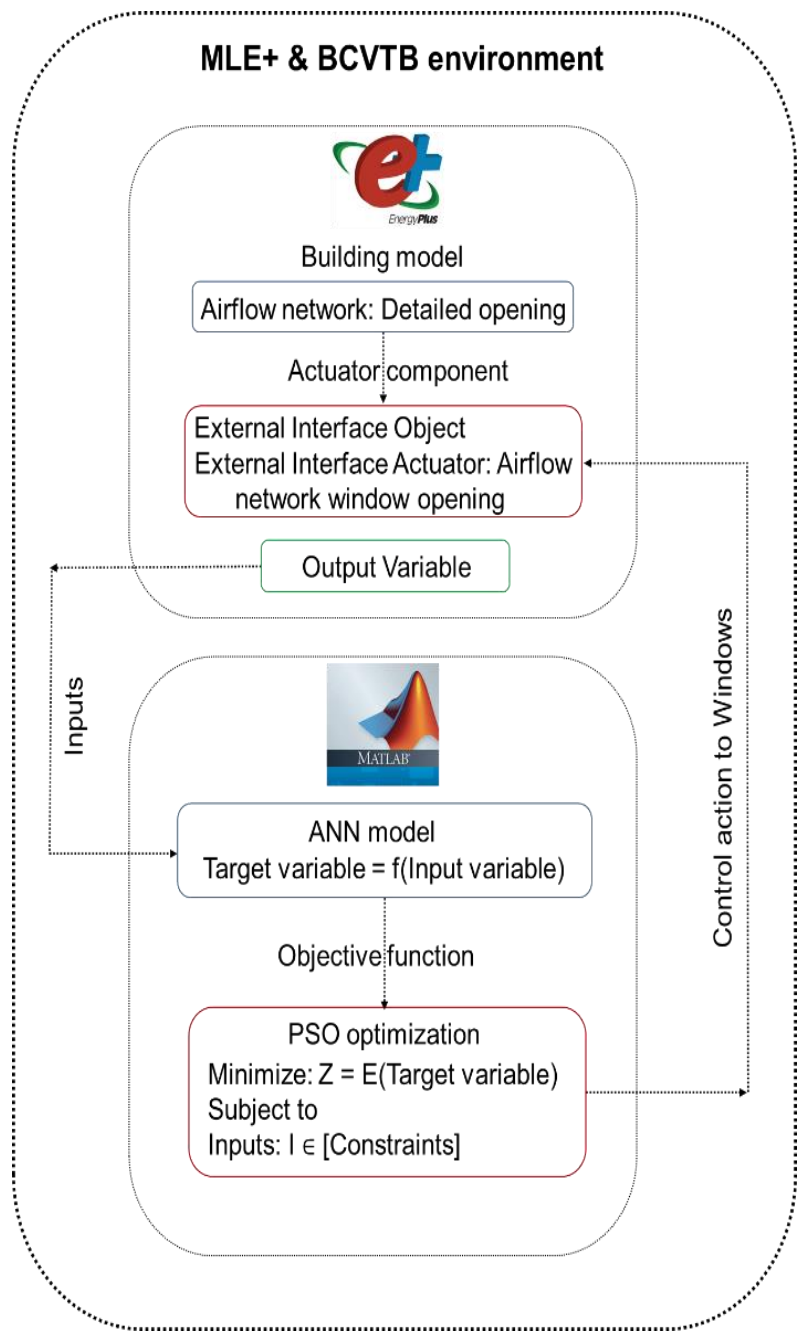

Figure 8: EnergyPlus Matlab co-simulation

Figure 8 shows the EnergyPlus Matlab co-simulation framework to implement the ANN model-based predictive controller. The figure shows that at first EnergyPlus starts simulation with the initial value and specified output of EnergyPlus is sent to Matlab for the optimization problem. After the optimization optimal solution (i.e., window opening position, and zone setpoint) is sent to the external interface of EnergyPlus for the simulation of the next time step. 


\section{Simulation results}

\section{Comparison of window opening schedule determined by rule-based and ANN model}

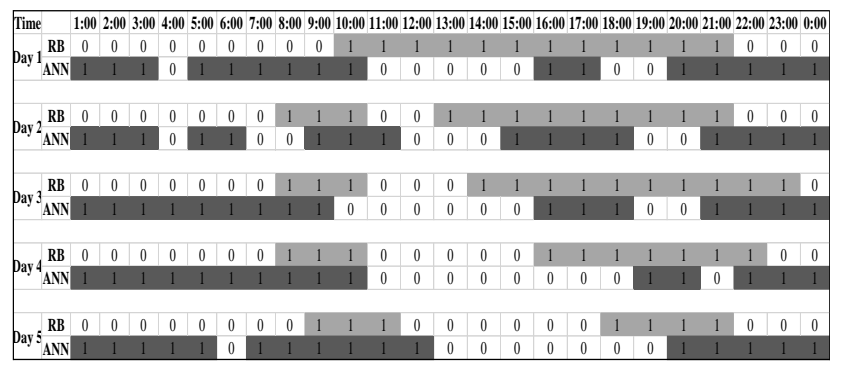

Figure 9: Window opening schedule predicted by simple rule-based and ANN model

Figure 9 shows the windows opening schedule predicted by simple rule-based and ANN model. The figure shows that ANN-based model predictive controller provides the open signal to the windows by minimizing the objective function especially during early morning and late night whereas, rule-based limits the opening of the windows because of its threshold temperature limit, i.e., between $22^{\circ} \mathrm{C}$ to $27^{\circ} \mathrm{C}$ at the same time.

\section{Comparison of average building operative temperature predicted by rule-based and ANN model}

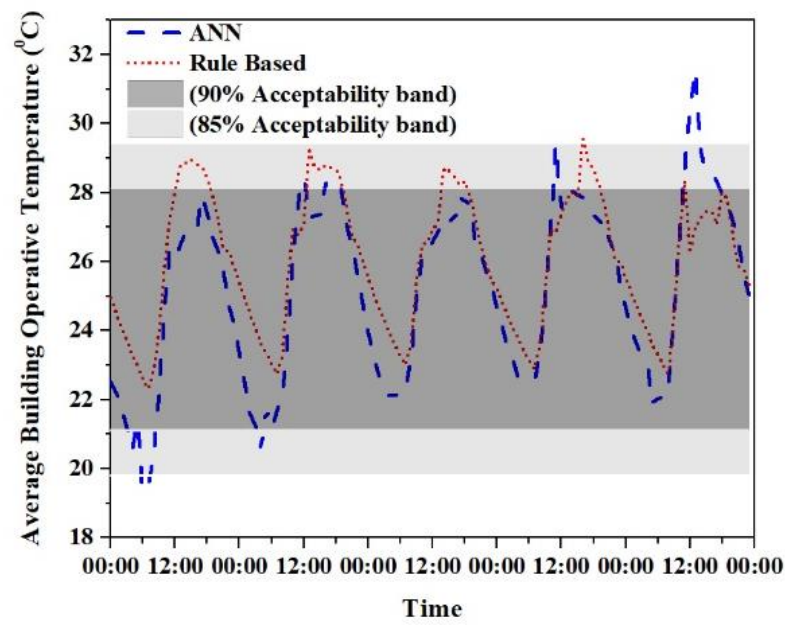

Figure 10: Average building operative temperature predicted by rule-based and ANN model control

Figure 10 shows the average building operative temperature predicted by the rule-based and ANN model controller. It can be observed that operative temperature predicted by both rule-based and ANN model controller falls in the range of acceptable thermal comfort temperature band. Operative temperature predicted by the ANN model tends towards the cooler side than that of predicted by the rule-based model during the night. This is because the ANN model opens the windows during the night, whereas, the rule-based model keeps it close. On day 5, operative temperature predicted by ANN model overshoots the thermal comfort band, this happens because ANN controller opens the window during noon (Figure 9) when the outdoor dry bulb temperature is beyond the acceptable mixed-mode operation criteria. Thermal comfort band is decided according to the IMAC
(India Model of Adaptive Thermal Comfort) (Manu, 2016) for mixed-mode buildings and can be written as:

$$
T_{\text {comfort }}=0.31 T_{a, \text { out }}+17.8^{\circ} \mathrm{C}
$$

Where $T_{a, \text { out }}$ is the 30 day running outdoor dry bulb temperature. Ranges for $90 \%$ and $85 \%$ acceptability are $T_{\text {comfort }} \pm 3.5^{\circ} \mathrm{C}$ and $T_{\text {comfort }} \pm 4.5^{\circ} \mathrm{C}$ respectively.

\section{Comparison of Exceedance metric between rule- based and ANN model-based predictive controller}

Exceedance is calculated using the $T_{\text {comfort }} \pm 3.5^{\circ} \mathrm{C}$ (90\% acceptability of thermal comfort temperature) and can be represented as

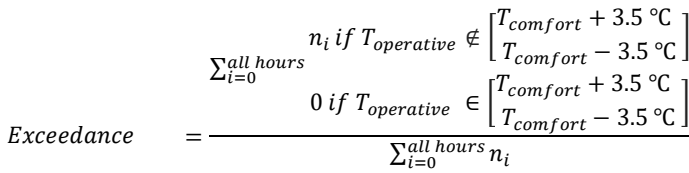

Where $n_{i}$ is the number of occupants present for a given hour. Exceedance metric weights the hours of exceedance by their occupancy and can be calculated using outputs from PMV/PPD and adaptive thermal comfort models (Borgeson, 2011). In the adaptive thermal comfort model comfort temperature is a point and it is possible that operative temperature calculated by EnergyPlus never attain the specific comfort temperature point. That is why the range is required in case of adaptive thermal comfort models for exceedance calculation as presented in eq. (2).

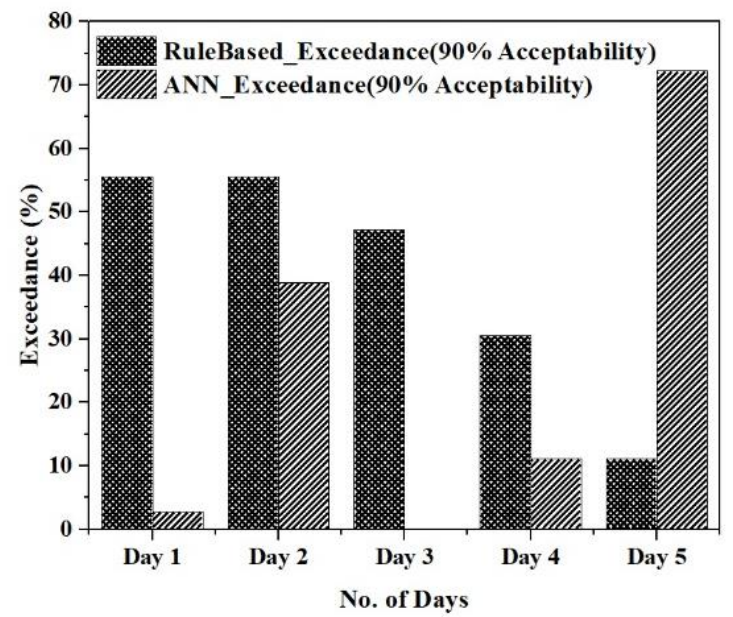

Figure 11: comparison of exceedance predicted by rulebased and ANN model

Figure 11 shows the exceedance calculated using the rulebased and ANN model predicted operative temperature. It can be observed that the ANN model has less exceedance value compared to a rule-based model which signifies better occupant thermal satisfaction. As the number of hours with the operative temperature outside the thermal comfort band increases, exceedance value increases. Figure 10 shows that for first four-day operative temperature predicted by the ANN model lies most of the time within thermal comfort band that is why ANN model has less exceedance value. Whereas, operative temperature predicted by the rule-based model goes beyond the thermal comfort band during the occupied period which leads to higher exceedance value. On day 
five operative temperature predicted by the ANN model is higher compared to that predicted by the rule-based model and goes beyond the thermal comfort band (Figure 10). This causes the exceedance value predicted by the ANN model to surpass the exceedance value predicted by the rule-based model on day five (Figure 11). The reason behind this anomaly could be the high air velocity during the afternoon. Optimization function seeing the high air velocity opens the window to minimize the cooling energy.

\section{Comparison of cooling energy predicted by rule- based and ANN model}

Figure 12 shows the building cooling energy consumption pattern along with the window opening schedule for the ANN model. It can be observed that when the window remains open, cooling energy drops compared to its closed position. Low energy consumption is observed during the window open position because of the increased set-point temperature of the thermally occupied zones. Thermostat set-point temperature of the thermally occupied zones is determined by the solution of the optimization problem by keeping the zone operative temperature between $26^{\circ} \mathrm{C}$ and $24^{\circ} \mathrm{C}$ for the window open and closed position respectively.

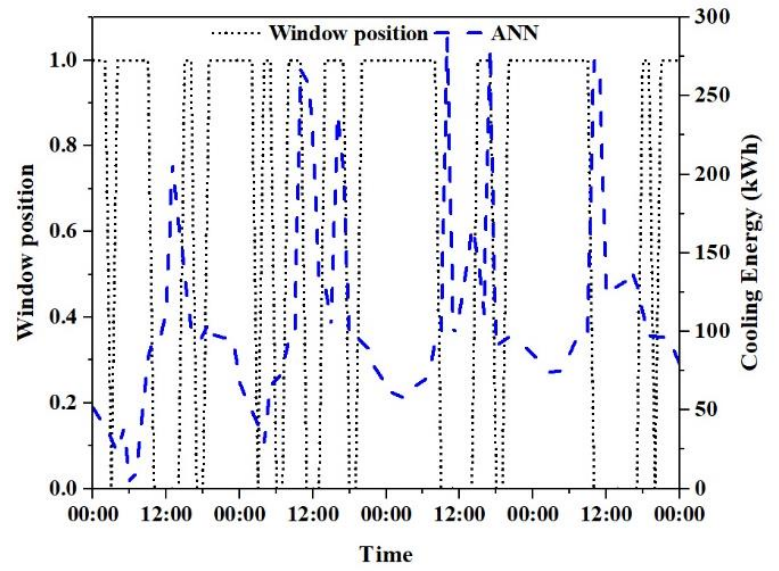

Figure 12: Cooling energy consumption with window opening schedule

Figure 13 shows the cooling energy comparison predicted by rule-based and ANN model. The figure shows that cooling energy predicted by the rule-based model is higher than that of predicted by the ANN model for the simulation period. Initially, the percentage difference between the energy consumption predicted by both the models (rule-based and ANN model) is higher, but it gradually decreases with time. For day one cooling energy saving is highest $(42.7 \%)$ because constraint rules force the rule-based model to give a close signal to windows during the night when the advantage of outdoor environment could be taken whereas, ANN model, by minimizing the cooling energy provides an open signal to windows to take advantage of the outdoor environment. For day two, three and four, the percentage of cooling energy savings are $26.6 \%, 28.5 \%$, and $21 \%$ respectively. The cause of a significant drop in energy savings compared to day one is the outdoor dry bulb temperature.
For day one dry bulb temperature is low (Figure 4) compared to the other days. Due to low dry bulb temperature sensible cooling load is low and consecutively there is less energy consumption. For day two, three and four outdoor dry bulb temperature is higher compared to day one which causes higher sensible cooling load, and therefore there are less energy savings. For day five, the percentage difference between cooling energy predicted by rule-based and ANN model is lowest (11\%) because ANN model provides an open signal to the window, during the afternoon when the outdoor environment lies outside the thermal comfort band.

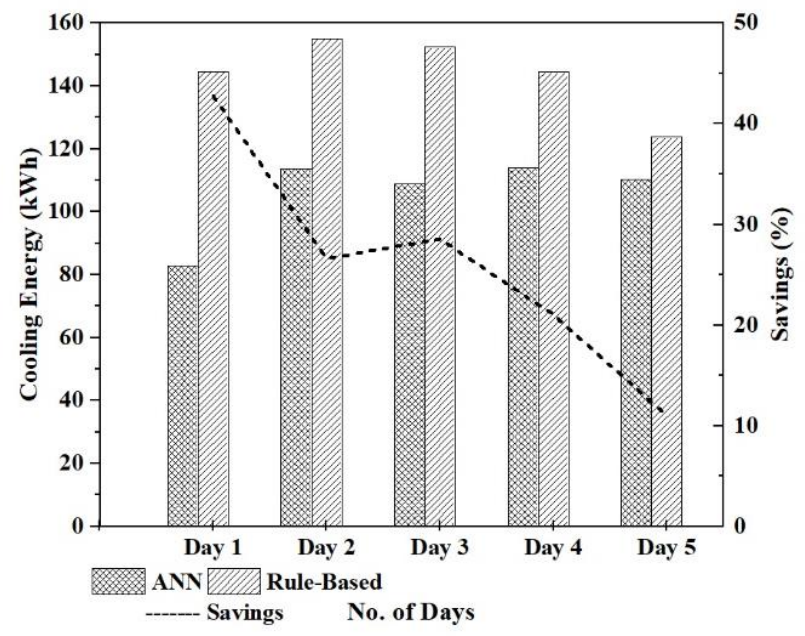

Figure 13: Cooling energy comparison predicted by rule-based and ANN model

\section{Conclusions}

This paper presents a comparative performance analysis of ANN-based model predictive control and rule-based control for implementing the mixed-mode strategies for a prototype building. The optimal control sequences (binary windows open/close) and zone set-point temperature for occupied zones are generated through PSO. Windows operation schedules are significantly different from that generated by rules-based control which helps in improving thermal comfort and saving cooling energy. The proposed ANN-based method allows simulation of optimally controlled sequences in consideration of both energy optimization and comfort maintenance and provides insights into the relevance of different windows operation schedules. The following conclusion can be drawn from the simulation results:

- Rule-based controller predicts a lesser night window opening schedule compared to the ANN model because of the strict rule of actuating the windows within the dry bulb temperature band of $22^{\circ} \mathrm{C}$ to $27^{\circ} \mathrm{C}$. However, the ANN model provides an open signal to windows by minimizing cooling energy consumption.

- Building average operative temperature predicted by ANN model lies within the $90 \%$ acceptability limit of adaptive thermal comfort band for most of the time of simulation period whereas, operative temperature predicted by rule-based model crosses the $90 \%$ 
acceptable thermal comfort band during afternoon hours on each day of the simulation period.

- To access the comfort level over the time predicted by both the models, exceedance is calculated. Exceedance value predicted by the ANN-based model predictive control is lower than that predicted by the rule-based control. So it can be concluded that the ANN-based model provides better thermal comfort.

- Comparison of cooling energy consumption predicted by both the model show that ANN predicts lower cooling energy consumption compared to the rulebased model, and minimum and maximum cooling energy savings for the simulation period are $11 \%$ and $42.7 \%$ respectively.

Efforts in this study are focused on developing a simplified ANN-PSO based framework to facilitate the implementation of mixed-mode operation strategies in multi-zone buildings. Furthermore, the proposed method may help in implementing the mixed-mode strategies efficiently in the real-time controller.

\section{Nomenclature}

$\begin{array}{ll}T_{\text {comfort }} & \text { Comfort temperature }\left({ }^{\circ} \mathrm{C}\right) \\ T_{a, \text { out }} & \text { 30 day outdoor running mean air } \\ & \text { temperature }\left({ }^{\circ} \mathrm{C}\right) \\ T_{\text {operative }} & \text { Operative temperature }\left({ }^{\circ} \mathrm{C}\right) \\ n_{i} & \text { Number of occupants } \\ I & \text { Integer } \\ E & \text { Cooling energy function } \\ Z & \text { Objective function } \\ \text { AHU } & \text { Air Handling Unit } \\ \text { ANN } & \text { Artificial Neural Network } \\ \text { BCVTB } & \text { Building Control Virtual Test Bed } \\ \text { HVAC } & \text { Heating Ventilation and Air } \\ \text { ISHRAE } & \text { Conditioning } \\ & \text { Indian Society of Heating Refrigerating } \\ \text { PMV } & \text { and Air Conditioning Engineers } \\ \text { PPD } & \text { Predicted Mean Vote } \\ \text { VAV } & \text { Predicted Percent Dissatisfied } \\ & \text { Variable Air Volume }\end{array}$

\section{References}

Borgeson, S., and Brager, G. (2011). Comfort standards and variations in exceedance for mixed mode buildings. Building Research \& Information 39(2), 118-133.

Braun, J.E. (1990). Reducing energy costs and peak electrical demand through optimal control of building thermal storage. ASHRAE Trans 96(2), 876-88.

Jianjun, H., Panagiota, K. (2014). A state-space modeling approach and multi-level optimization algorithm for predictive control of multi-zone buildings with mixedmode cooling, Building and Environment 80, 259273.
Manu, S., Shukla, Y., Rawal, R., Thomas, L. E., and Dear, R. D. (2016). Field studies of thermal comfort across multiple climate zones for the subcontinent: India Model for Adaptive Comfort (IMAC). Building and Environment 98, 55-70

May-Ostendorp, P., Henze, G.P., Corbin, C.D., Rajagopalan, B., and Felsmann, C. (2011). Model predictive control of mixed-mode buildings with rule extraction. Build Environ 46(3), 428-37.

Moré, J. J. (1978). The Levenberg-Marquardt algorithm: implementation and theory. In Numerical analysis, 105-116.

McConahey, E. (2008). Mixed mode ventilation: finding the right mix. ASHRAE Journal 50, 36-48.

Spindler, H.C., and Norford, L.K. (2009). Naturally ventilated and mixed-mode buildings - part I: thermal modeling. Build Environ a;44(4), 736-49.

Wetter, M., Nouidui, T.S., Haves, P., Zhang, R., Li, Z. (2011). Building controls virtual test bed interface.

Zhao, J., Lam, K.P., Ydstie, B. E., and Karaguzel, O.T. (2015). EnergyPlus model-based predictive control within design-build-operate energy information modelling and infrastructure. Journal of Building Performance Simulation 8(3), 121-134. 